\title{
American Disproportionality: A Historical Analysis of Partisan Bias in Elections to the U.S. House of Representatives
}

\author{
Bernard Tamas
}

\begin{abstract}
In this article, I introduce a new index for measuring partisan bias called the Directional Proportionality Index (DPIx) and apply it to elections to the House of Representatives since 1900. Derived from the Loosemore-Hanby index, the novelty of DPIx lies in the fact that it synthesizes a proportionality index with a measure of partisan symmetry. I then apply this index to House elections from 1900 to 2016 at the national level as well as in several states, and I also tested it against hypothetical circumstances in which the negative effects of gerrymandering are completely eliminated. The results demonstrate that while gerrymandering is currently producing a pro-Republican bias, this asymmetrical disproportionality has regularly existed in House elections over the past century and was often much more severe. The evidence suggests that short of substantial electoral reform, asymmetrical disproportionality is likely to remain a fundamental characteristic of American electoral politics.
\end{abstract}

Keywords: proportionality, partisan bias, partisan symmetry, electoral system, electoral reform

\section{INTRODUCTION}

$\mathbf{O}$ NE OF THE CENTRAL CONCEPTS in the philosophy behind representative democracy is "one person, one vote." Built onto the basic notion of human equality and especially equality before the law, and for United States citizens rooted in the Equal Protection Clause of the Fourteenth Amendment, this concept not only leads to the conclusion that all citizens should have equal opportunity to vote but also that their vote should count equally. In Baker v. Carr (1962) and Reynolds v. Sims (1964), for example, the Supreme Court famously required all states to make all legislative districts equal in population, to preserve one person, one vote. Effectively, the Court was arguing that having

Bernard Tamas is an assistant professor in the Department of Political Science at Valdosta State University in Valdosta, Georgia. districts of unequal populations diluted the votes of those living in more populous districts, and that the votes of some people (in this case, mostly people living in rural areas) were treated as more valuable and produced a greater level of representation than the votes of those who happen to live in districts with more citizens.

This concept of voting equality, and of not diluting votes, is a bedrock onto which much of the electoral systems literature is built. Nonetheless, this study of electoral systems - or the overarching rules that define how the vote determines which candidates and parties are awarded elected positions-is significantly divided between those who study American politics and those who study political systems more comparatively. Within the American politics literature, the focus is primarily on partisan symmetry, or the degree to which the election rules are fair to both major parties. Gelman and King (1994), for example, focus on partisan bias, which they define as 
the degree to which the American electoral system favors one party over the other, while Stephanopoulos and McGhee's efficiency gap (2015) compares how many Democratic and Republican voters are "wasting" their votes each election owing to gerrymandering. Conversely, the primary focus within the comparative electoral systems field is proportionality, or the degree to which the percent seats a party is allocated reflects the percent votes it receives. In this case, there are a range of measures to determine proportionality, though likely the most widely used is the Gallagher index (Gallagher 1991; Lijphart 1994).

These two approaches also lead to different conclusions about how electoral reform could improve representation in the United States. Those promoting the partisan symmetry approach tend to emphasize reform that eliminates severe gerrymandering. Indeed, this literature has grown as a direct consequence of the United States Supreme Court rejecting disproportionality as a proper standard for judging gerrymandering and therefore provides an approach that measures how fairly the system treats each political party (Grofman and King 2007). Those taking a more comparative approach would often emphasize that the problems with the American electoral system are much deeper than the shenanigans of state governments during redistricting, and that more fundamental change, such as the adoption of some form of proportional representation (PR), is necessary (Amy 2002; Barber 2001).

I would argue, however, that these approaches need not be treated as distinct. Both speak to different aspects of equality. The former is primarily about the fairness of the system towards each party while the latter is about how much the percent vote for each political party is counted equally when legislative seats are allocated. But, I would argue, if one focuses on the equal influence of votes instead of the equal treatment of parties, then proportionality becomes fundamental to the concept of symmetry.

Put more specifically, I argue that proportionality is central to the concept of one person, one vote. If $30 \%$ of voters selected Party A and this party received $20 \%$ of legislative seats, and if $35 \%$ of voters selected Party B and this party received $50 \%$ of seats, effectively the system treated these voters unequally: each vote for Party B was treated as more valuable than each vote for Party A. This is true regardless of why there is this discrepancy, since supporters of Party A have been injured with reduced influence over their government. The symmetry of this disproportionality also matters. If the electoral system is disproportional but that disproportionality fluctuates randomly each election, then the reduced influence for supporters of Party A in this election will likely be followed by increased influence by these voters in subsequent elections. However, if the system repeatedly benefits Party B over Party A, then the injury to supporters of Party A would compound itself over time. In this way, any system that is fair to votersthat is, treats their votes as equal-would have some combination of proportionality and symmetry.

In this article, I introduce a new index for measuring partisan bias that I have developed, called the Directional Proportionality Index (DPIx). Derived from the Loosemore-Hanby index (Loosemore and Hanby 1971), the novelty of DPIx lies in the fact that it synthesizes a proportionality index with a measure of partisan symmetry. Unlike most symmetry measures, DPIx also factors in the impact of votes for all candidates, even independent and third-party candidates, while focusing on the relative bias between two sets of parties. For this study of American elections, I focus on the relative bias between the largest parties, the Republicans and Democrats, which I call the "two-party bias."

Using House election results collected from Dubin (1998) and the Federal Election Commission website, www.fec.gov, I then apply DPIx to elections to the U.S. House of Representatives since 1900 three different ways. First, I demonstrate the evolution of overall two-party bias of all House elections over the past 118 years. Second, I conduct the same analysis for elections to the U.S. House of Representatives since 1900 in three states: New York, Pennsylvania, and North Carolina. Third, I compare the overall two-party bias of House elections since 1900 with what that bias would have been if the voting patterns were the same but the U.S. had two different types of PR systems, one that treated the entire United States as a single, multimember district, and the other in which each state was a separate, multimember district. This last approach provides two points of comparison that can be treated as expected values: the national-PR system tests show the overall results of House elections each year if these elections were proportional and symmetrical, and the state-PR system shows how the system would look if, at each state level, House elections were proportional and symmetrical. Finally, this last analysis provides a sense of how 
fundamental electoral reform might affect proportionality and symmetry in American elections.

Using this approach, I find significant evidence that U.S. House elections currently have a proRepublican bias and that redistricting after the 2010 census is one likely cause of that bias. However, I also find that this recent partisan bias is not unique. To the contrary, House elections have had long stretches of two-party bias during most of the last century, and that asymmetrical disproportionality was often much more severe than today. Over the twentieth century the Democratic Party, not the Republican Party, gained the most from this bias. The evidence presented below also shows that even if each state had elections that were proportional and symmetrical, the overall results of House elections would have still been deeply biased through most of the twentieth century. This final result strongly suggests that asymmetrical disproportionality in American elections is more fundamental than the manipulation of district lines, and moreover, that significant electoral reform based on state-level PR elections would inadequately address two-party bias within the American electoral system.

\section{DISPROPORTIONALITY AND ASYMMETRY}

Designed in the late eighteenth century and modified only incrementally over the next two centuries, the United States has a majoritarian electoral system that hurts representation in a range of ways. In the electoral systems literature, which tends to examine the impact of election rules on how votes translate into seats from a comparative perspective, the emphasis is on disproportionality, or the degree to which the percent of seats that each party wins is not proportional to the percent of votes each party receives (Farrell 2011). The most general finding, considered highly robust, is that single-member plurality (SMP) electoral systems are much more disproportional than proportional representation systems (Gallagher and Mitchell 2005).

Disproportionality also clearly exists throughout the various parts of the American electoral system, which was dramatically highlighted in 2016 when Donald Trump won the presidency with far less than a plurality of votes. While this disproportionality is most structurally severe in elections to the United States Senate, it also exists in elections to the United States House of Representatives. It not only hurts American third parties (Rosenstone 1984; Tamas 2018) but also shifts the relative strength of the major parties, sometimes to the point that the party receiving less than a plurality of votes nonetheless gains majority control over the institution (e.g., the 2012 election, when Democratic candidates gained more votes but the Republicans won 33 more seats.)

There are two primary reasons for the high disproportionality. The first is Duverger's Law (Duverger 1954), or the argument that SMP favors the two largest parties. In other words, in countries like Canada, the United States, and the United Kingdom, the largest parties tend to gain a significantly higher percent of seats than the votes they receive, and moreover, smaller parties tend to be allocated a lower percent of seats than their voter support. The second reason is that since SMP translates votes into seats based on the geographic distribution of votes, the relationship between the amount of public support a party has and the percent of elected positions it receives is indirect. Thus, if a country has two main parties with roughly equal levels of public support, and one of those parties has support more concentrated into a smaller number of districts, that party will tend to have a lower percent of seats compared to its percent vote. In both ways, then, many voters can be underrepresented in government. As one party gains a greater number of seats, effectively the influence of its constituents is inflated while other voters are underrepresented in government.

Because proportionality is so central to the study of electoral systems, scholars in this area have developed a range of indexes to measure it. Likely the two most important are the Loosemore-Hanby index and the Gallagher index. The LoosemoreHanby index is calculated as follows. For each party in a legislative election, the absolute value of the percent votes they received minus the percent seats they were allocated is calculated. These figures are then summed and then divided by two (Loosemore and Hanby 1971).

A great advantage of Loosemore-Hanby, besides its simplicity, is that it can be interpreted directly. A Loosemore-Hanby of 5 quite literally means that for $5 \%$ of the voting population their vote did not translate into seats for the parties that they had voted for. Nonetheless, Loosemore-Hanby has fallen out of favor among electoral system scholars for two 
main reasons. The first is that it fails the Dalton's principle of transfers (Monroe 1994), or the idea that if the percent of seats a relatively stronger party receives increases, the measure should reflect that change by also increasing. For LoosemoreHanby, it often does not. The second is more a question of interpretation related to the least supported parties. Since the measure is in absolute terms, it will show an increased disproportionality when there are a larger number of smaller parties that receive few or no seats.

An alternative measure, more widely used by electoral system scholars, is the Gallagher index (Gallagher 1991), which is also often referred to as the least square method. Indeed, it looks very much like some of the basic equations behind ordinary least squares (OLS) regression. For each party running candidates for a legislative body, whether a parliament, congress, or regional legislature, the Gallagher index is calculated by first subtracting the percent vote each party receives from the percent of seats it wins, and then squaring each of these differences. These squared differences are then summed, that total is divided by two, and then the square root of that quotient is found.

Because it squares the differences between votes and seats before summing them, the Gallagher index emphasizes the biggest differences between each vote percent and seat percent, which in turn tends to emphasize the largest parties. If one party receives $35 \%$ of the vote but only $30 \%$ of the seats while another, much smaller party receives $4 \%$ of the vote but no seats, one could argue that the supporters of the latter party were more severely underrepresented, since these voters gained absolutely no representation. But from the perspective of those who promote the Gallagher index, the difference for the larger party is much more important, which should be reflected in the result of the index.

Despite being the most widely used measure within the electoral systems literature, the Gallagher index also has its limitations. The first is that its interpretation is much less intuitive than LoosemoreHanby. A Gallagher index of 5 can be compared to a Gallagher index of 3 , but neither figure has a specific interpretation that can be described clearly to a nonspecialist, and moreover, these results are unrelated to the percent of voters who are underrepresented in government. The second issue, quite the opposite of Loosemore-Hanby, is that it understates the underrepresentation of voters who had selected small parties that received few seats. Thus, despite its wide use within the comparative politics field, for the purposes of measuring the percent of voters that are underrepresented in government, it has important weaknesses.

While the proportionality scales have helped improve political scientists' understanding of how electoral systems affect the workings of democracies across the world, they have a specific weakness when applied to the American context. Since they are not directional, they cannot provide much input on how gerrymandering impacts representation. To say that in 2016 Pennsylvania elections to the state legislature or U.S. House of Representatives had a particular Gallagher or LoosemoreHanby index says little about how the manipulations by Republican state legislators had impacted elections there. Since the results are always positive numbers, regardless of what party is benefiting, and since they are also measuring the underrepresentation of those who voted for third-party candidates, there is little way with this class of measures to determine if gerrymandering is producing an unfair Republican advantage vis-à-vis Democrats.

In response to these problems, scholars of American politics have shifted their focus to partisan symmetry. This concept is usually couched in the idea of electoral fairness, or when the rules apply to all candidates and parties equally. An example, taken from Grofman and King (2007), is that in an SMP system, at the district level, the candidate who gets the most votes wins. This rule applies regardless of who the candidate is or what party she represents. This argument could be generalized to a group of districts, such as the set of congressional districts in a state. Symmetry, and therefore fairness, would be achieved if for each party the same percent of votes would lead to the same percent of seats. In other words, if a party receives $55 \%$ of the vote and $70 \%$ of the seats, this is not unfair if any party that received $55 \%$ of the vote would have been awarded $70 \%$ of the seats. However, if one party systematically receives a higher percent of seats than its percent of votes, then the system is asymmetrical and therefore unfair. In this way, for example, gerrymandering produces not just disproportionality but also unfairness, since it systematically increases the seats for one major party but not the other.

Likely the best-known symmetry measure is Gelman and King's indicator of partisan bias (Gelman and King 1994), which builds on this notion of 
fairness. A powerful tool for measuring the twoparty fairness of specific SMP systems, it is rooted in a history of research in this area (Grofman and King 2007), influenced by their previous work on incumbency advantage (Gelman and King 1990), and used to develop a general framework for analyzing legislative elections (Gelman and King 1994).

Gelman and King go very far to distinguish their measure from all measures of proportionality. For them, the issue is electoral fairness, or whether the rules apply equally for all candidates and parties. In this definition, if one party receives $55 \%$ of the vote and is awarded $80 \%$ of the seats, there is no partisan bias as long as the rules are set up so that any party that received $55 \%$ of the vote would be awarded $80 \%$ of the seats. And if a single party repeatedly received $55 \%$ of the vote and was repeatedly awarded this overwhelming control over the legislative branch in question, this would still be fair, since hypothetically any other party could have received $55 \%$ of the vote and been awarded this high number of seats.

I would argue, however, that from the perspective of counting each vote as equal, this scenario is not fair at all. Quite the opposite, when a system is repeatedly disproportional in one party's favor, regardless of reason, its supporters gain an increased influence over government policy compared to other voters. Continuing with the example above, if in a two-party system the second party consistently receives $45 \%$ of the vote but only $20 \%$ of the seats, those supporters of the second party are being severely and repeatedly underrepresented in government, and their policy concerns are likely being largely ignored. The fact that, hypothetically, they would also receive $80 \%$ of the seats if they could gain another $10 \%$ of the vote does not change how this directional disproportionality leads directly to these voters being underrepresented and therefore being treated unfairly.

Another symmetry measure, developed in direct response to Gelman and King's party symmetry measure, is the efficiency gap (Stephanopoulos and McGhee 2015). In this case, the goal of the measure is to determine if supporters of one major party have significantly more influence over election results than supporters of the other major party. Stephanopoulos and McGhee attempt to accomplish this by focusing on wasted votes. Supporters of a party can waste votes one of two ways. If they vote for a candidate who loses, then it is a wasted vote. Simi- larly, every vote that is greater than the votes needed for a candidate to win is also a wasted vote. So, if a district-level election has 100,000 votes with 40,000 votes for Party A's candidate and 60,000 votes for Party B's candidate, then Party A had 40,000 and Party B had 19,999 (that is, 60,000 minus 50,001) wasted votes. Combined across all the districts in a state, if supporters of one party are wasting fewer votes than supporters of another party, then the system is biased in favor of the former party.

The efficiency gap is clearly designed in response to the general nature of gerrymandering, in which the party running a state government can pack many supporters of the other party into a single district or dilute (i.e., "crack") their support across many districts (Seabrook 2017). If a party's supporters are packed into a single district, then that party will win by a large percent of votes, wasting many votes that could have been used to elect other candidates. Conversely, if a party's supporters are diluted across districts, then their votes would also be considered wasted.

However, the weakness of this measure compared to a proportionality index becomes clear when one moves past cases of packing and cracking. As one obvious example, let's say there is a state in which $95 \%$ of voters across every district support one party, and that party wins every seat. This would be considered a rather proportional result, since the party with $100 \%$ of the seats received nearly $100 \%$ of the vote. But, oddly, it would be considered an inefficient result, since this widely supported party is "wasting" approximately $44 \%$ of votes. Conversely, if in the same state a single party won every single seat by $51 \%$ of the vote, this result would be considered extremely disproportional, and it would also be considered inefficient, since the losing party is also wasting all of its votes. In other words, the efficiency gap cannot distinguish between two obviously very different scenarios, even though in the latter case $49 \%$ of voters have no party representation.

In sum, proportionality scales tell us a great deal about how well an electoral system leads to voters being equally represented in government, but they are problematic in that they do not indicate how these systems are biased towards one set of voters or another. Conversely, partisan symmetry measures provide a sense of which major party is gaining an unfair advantage, but these measures leave out the fundamental concept of how equally voters are being represented. 
My solution to this issue is to combine a measure of partisan symmetry within a proportionality index. Derived from the Loosemore-Hanby index, I call this measure the Directional Proportionality Index, or DPIx. DPIx is specifically designed to measure the relative seat boost of two sets of parties. While it can be applied to a range of scenarios, in this article I focus entirely on the relative seat boost for Republican candidates over Democratic candidates in House elections. DPIx is calculated as:

$$
\frac{\left(S_{1}-V_{1}\right)-\left(S_{2}-V_{2}\right)}{2}
$$

with:

- $S_{1}$ - the total percent seats won by all parties in the first set;

- $\mathrm{V}_{1}$-the total percent vote for all parties in the first set;

- $\mathrm{S}_{2}$ - the total percent seats won by all parties in the second set; and

- $\mathrm{V}_{2}$ - the total percent vote for all parties in the second set.

For the calculation of each percent, the denominator is always the total number of votes cast in an election or the total number of seats in the legislature, not just the votes cast for the parties studied and the number of seats these parties won. This avoids inflating the results unnecessarily in circumstances in which there are stronger third parties, such as during the 1912 election in the United States or most elections in other SMP countries.

DPIx is designed to be a very simple, easily applied measure. It can be used, for example, to measure the relative bias for Republican candidates compared to Democratic candidates. In the 2012 election, the first election after the last reapportionment, for example, Democratic House candidates received $49.16 \%$ of the vote but only $46.2 \%$ of the House seats. Conversely, Republican candidates received $48.14 \%$ of the vote-or one percent less than the Democrats-but were nonetheless awarded $53.79 \%$ of the House seats. In this case, the DPIx would be calculated as:

$$
\frac{(53.79-48.14)-(46.2-49.16)}{2}=4.31
$$

Another example is from a century before, during the 1912 election, when the insurgency by the Pro- gressive Party and other third parties pulled a significant number of votes from Republican candidates, which translated into a large victory for the Democratic Party. Specifically, Republican House candidates received $35.08 \%$ of the vote and only $30.80 \%$ of the seats. However, Democratic House candidates received $44.11 \%$ of the seats but won a dramatic $67.13 \%$ of the seats. The DPIx in this case would be measured as:

$$
\frac{(30.80-35.09)-(67.13-44.11)}{2}=-13.66
$$

Unlike most proportionality indexes, DPIx is also designed to be applied differently for different questions. For example, if one is testing the bias of a system in favor of the two largest parties, then the first set of parties in each system would be the two largest while the second set would be the rest, while the denominator for each percent would be the total number of votes or seats, including of independent candidates. ${ }^{1}$ Similarly, one can use it to measure the relative bias of the UK electoral system towards parties in different regions. It can also be used to measure the relative bias of a system between the two largest parties in an electoral system, such as the Conservatives and Labour in the UK or the Republicans and Democrats in the United States. In each case for each election, DPIx provides a directional result that specifies the relative bias towards one set of parties compared to the other.

Since the results show the relative asymmetric disproportionality of a system towards two sets of parties, each variation in the application of DPIx

\footnotetext{
${ }^{1}$ In this equation, I do not include the votes received and seats won by independent candidates as part of the votes received and seats won by third-party candidates; they would be included only as part of the total votes and seats when calcuating the percents. This is because I define independent and thirdparty candidates as distinct categories. More specifically, within the American party literature, third-party candidates are often defined as any candidate who is not nominated by the Democratic or the Republican Party (Rosenstone, Behr and Lazarus 1984). In this way, an independent candidate would be considered a third-party candidate. However, I would argue against this definition for two reasons. First, following the larger party literature, a political party is generally defined as an organization that runs candidates for elected office under a single label (Downs 1957; Epstein 1967). When a candidate is running as an independent, they are by definition not running under a party name, and therefore are not thirdparty candidates. Second, empirically, the patterns of activity and voter support for independent candidates are significantly different than for third-party candidates (Tamas 2018).
} 
produces a measure of a different type of partisan bias. In this article, I call the relative bias between the Republican and Democratic parties the "twoparty bias."

In single-member district systems, the DPIx is heavily influenced by the geographic distribution of the vote vis-à-vis district lines. Indeed, this is likely more of a factor than if a single party wins a large majority of the vote. This can be illustrated through a set of hypothetical examples. As one example, if in a two-party system the first party receives $90 \%$ of the vote and wins all the seats while the second party receives $10 \%$ of the vote and wins no seats, then the DPIx between these two parties would be 10 or -10 , depending on which party was treated as the first set. However, as a second example, let us say that the first party receives $90 \%$ of the vote while the second receives $10 \%$ of the vote, but the vote for the second party is geographically concentrated in a small percent of districts, leading it to win $10 \%$ of the seats. In this case, despite the first party receiving a large percent of the vote, the DPIx would be 0 , since the votes received and seats won would be exactly proportional. A third hypothetical example would be if the first party receives $55 \%$ of the vote but that vote is distributed equally across districts. Specifically, the strongest party wins $100 \%$ of the seats by $55 \%$ percent of the vote. In this case, the DPIx would be a whopping 45 . In other words, the percent vote for the strongest party is not necessarily a key factor affecting the DPIx. Often, the more important factor is the relative geographic distribution of party support across districts.

Like the proportionality indexes from which it is derived, DPIx is a measure of the relationship between the actual vote and the party distribution of seats in a legislature. In this way, it is not a perfect representation of how citizen preferences influence actual representation, both because not all citizens vote and because various factors, including ballot access restrictions, determine what parties voters can actually vote for. As one example, if a significant percent of the population supports social democratic policies but there is no social democratic party to vote for on the ballot, then effectively these voters are being underrepresented within the system. However, DPIx cannot measure this underrepresentation. Another example is when a district is uncontested, that is, there is only one candidate on the ballot. In this case, like with the voters having fewer candidate choices than they might prefer, there is no attempt with DPIx to estimate how the vote might differ if there were more candidates on the ballot. $^{2}$

In this study, I apply the DPIx to elections to the House of Representatives from 1900 to 2016. In this case, the American electoral system would be considered proportional and symmetrical if the DPIx was small in absolute terms or the direction of any seat boost would be largely random across successive elections. Conversely, a high level of two-party bias would exist if the DPIx is large in absolute terms and favoring the same party in successive elections. As the results below will show, while elections to the House of Representatives currently have a proRepublican bias, these elections have had a long history of two-party bias, and generally it was the Democratic voters who gained a boost of representation in the United States Congress.

\section{NATIONAL TWO-PARTY BIAS SINCE 1900}

Figure 1 demonstrates the overall level of disproportionality and asymmetry in House elections since 1900. Like the graphs below that show these same figures for individual states, positive numbers in Figure 1 mean that the election results were biased in the Republican Party's favor, or that the Republicans received a higher percent of seats than percent of votes in comparison to the Democratic Party. Conversely, negative numbers indicate that the election results were biased in the Democratic Party's favor. Figure 1 shows these results two ways: the DPIx each election year (solid line) and the moving average of the DPIx (dashed line), which is the average DPIx for each election and the previous four elections. Thus, for the 2016 election,

\footnotetext{
${ }^{2} \mathrm{~A}$ more serious version of this problem would be when state governments do not record votes when there is an uncontested race. For each individual district, this would bias the results towards the party of the lone candidate, since it would add nothing to the vote total but increase the seat total by one. In the United States, these types of races emerged almost exclusively in the South starting in 1958. From 1958 to 2016 there were 180 races like this, or in approximately nine districts per election. Since 1958, these races affected the two-party bias by an average of .09 (or less than one-tenth of a percent), and never more than .44 , or less than half a percent. In other words, while this could theoretically be a problem, in reality the impact of this form of reporting by Louisiana and a few other states is very small.
} 


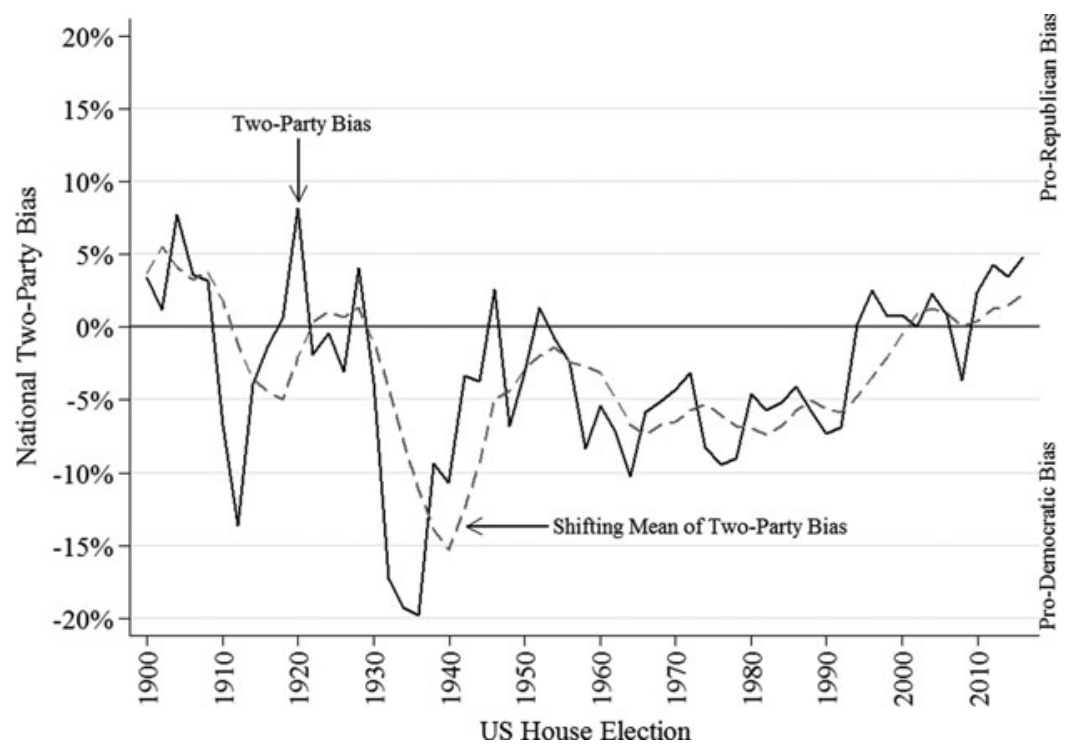

FIG. 1. Two-party bias in U.S. House elections, 1900-2018.

the moving average is the sum of each DPIx from 2008 to 2016 divided by five. The purpose of the moving average is to help distinguish erratic, shortterm shifts in disproportionality and symmetry from patterns that last for at least one full decade.

The graph reveals several aspects of disproportionality and asymmetry in U.S. House elections since 1900. The first is that the level of two-party bias has shifted considerably over this 118 -year period. The DPIx for each House election year moves widely, ranging from virtually zero (-.004) in 2002 to a pro-Republican bias of 8 in 1920 and a proDemocratic bias of -20 in 1936. (In other words, in 1920, relative to the Democrats, the Republicans gained $8 \%$ more seats than votes, and conversely, in 1936, the Democrats won a whopping $20 \%$ more House seats than votes, in comparison to the Republicans.) Moreover, the level and direction of disproportionality shifted dramatically by election, especially during the first half of the century. In 1904, the structure of House elections led to a pro-Republican bias of $8 \%$; in 1912, that structure led to a Democratic advantage of $14 \%$; and then in 1920 it was a pro-Republican bias again of $8 \%$.

Nonetheless, despite these significant shifts, for most of this history, the two-party bias favored the Democrats, not the Republicans. Over the twentieth century, the Democrats received a higher percent of seats than votes in three-fourths of House elections. From 1900 to 1998, U.S. House elections had an average Democratic Party bias of $-4.5 \%$. Put another way, there was never a pro-Republican bias of over $10 \%$ during the period studied, but this occurred six times in favor of the Democrats during the twentieth century, including twice (1934 and 1936) when that bias nearly reached $20 \%$.

The moving average of the DPIx suggests further that there were periods when each major party was gaining a higher percent of seats than votes in House elections. In the first decade of the twentieth century there was approximately a 5\% bias in the Republicans' favor. This shifted to approximately a 5\% advantage for the Democrats in the 1910s. One possible reason for this shift was the rise of significant third parties, especially the Progressives. Since the Progressives were largely a splinter from the Republican Party, they appear to have caused a split in what had previously been the Republican base of support, creating an electoral advantage for the Democrats over the Republicans. After House elections became much more symmetrical in the 1920s, the New Deal began a long period of the Democratic Party gaining a significant electoral advantage over the Republicans. Then, from 1994, when the Newt Gingrich-led Republicans regained control of both houses of Congress, until 2010, the system was largely symmetrical, with a small Republican bias of $0.7 \%$.

But then in 2012, or right after the last reapportionment of House districts and therefore redrawing of district lines by state legislatures, the Republican bias of the system jumped to an average of $4.2 \%$. 
During the 2016 election, that pro-Republican bias was $4.8 \%$. The moving average of the DPIx for 2016 was a lower $2.3 \%$, but this appears to have been caused by the moving average not yet catching up to the pro-Republican bounce that started in 2012 .

Combined, three main conclusions can be made from this figure. The first is that this evidence is consistent with the argument that Republicans have shifted American elections in their favor through gerrymandering during the 2010 reapportionment. The shift towards a pro-Republican bias is not smooth but instead a clear jump right after state legislatures across the country redrew their district lines. Second, that pro-Republican bias is not particularly large in historical perspective. The two-party bias for 2016 is $4.8 \%$. In comparison, the mean and median absolute value of the twoparty biases from 1900 to 2014 were respectively $4.2 \%$ and $5.5 \%$. Third, for most of the twentieth century, the Democrats were the party most often favored in congressional elections by the American SMP system, and that pro-Democratic bias was often much more dramatic than the current bias towards the Republican Party.

\section{STATE-LEVEL PARTISAN BIAS}

Figures 2 through 5 show the movement of the DPIx in House elections in three states: New
York, Pennsylvania, and North Carolina. My primary reason for examining the results for these states is to test the impact of gerrymandering in the latter two. Gerrymandering would not only cause a pro-Republican two-party bias in these states, but one could expect the DPIx to spike upward after the 2010 reapportionment. I use New York as a point of comparison.

Figure 2 shows the DPIx and the moving average of the DPIx in New York races to the U.S. House of Representatives since 1900. Like at the national level, the bias of House races in New York could shift widely from election to election. In 1912, for example, Democratic Party candidates gained 20\% more seats than their percent vote compared to the gain of Republican candidates, and then in 1920, there was a Republican two-party bias of $17 \%$. Similarly, as suggested by the moving average, there appear to have been different periods in the two-party bias within New York. Until the 1920s, the twoparty bias favored the Republicans. Starting around 1922 until the early 1940s, the Democratic Party was gaining the greater boost of seats compared to votes in New York. That bias flipped back in the Republicans' favor in the 1940s, and then it reverted to a Democratic advantage in the mid-1960s. Since around 2002, New York State has experienced a $10 \%$ pro-Democratic two-party bias.

As Figure 3 shows, like New York, the two-party bias in Pennsylvania has gone through significant shifting since 1900. From 1900 until the 1930s, it

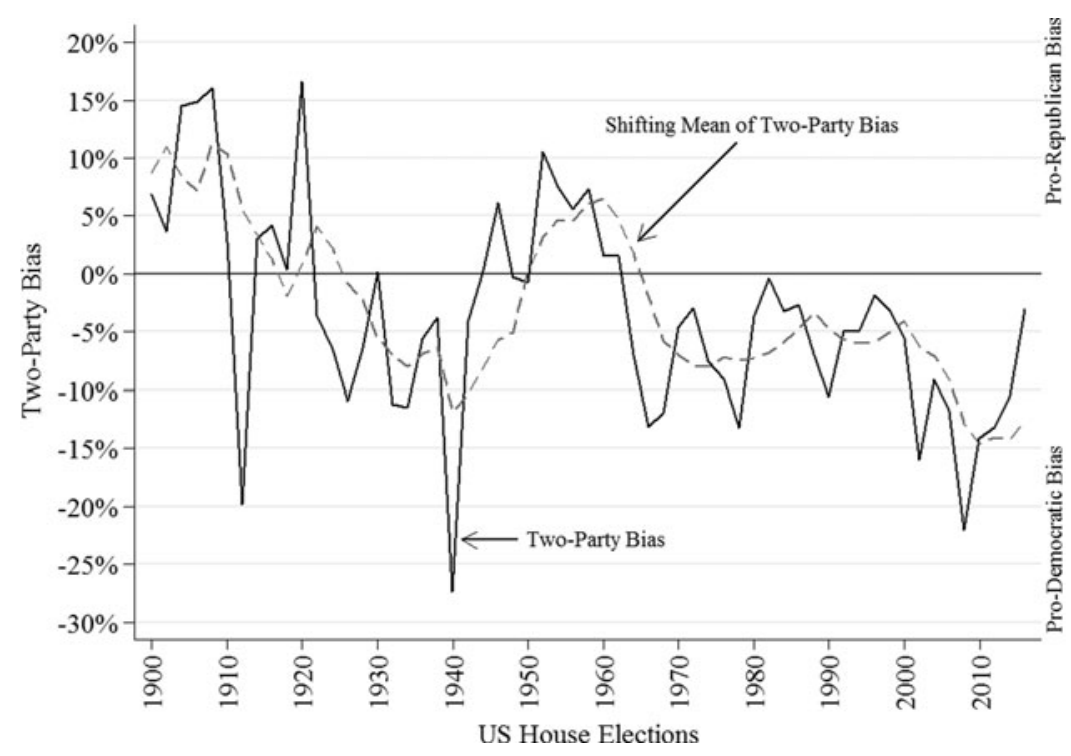

FIG. 2. Two-party bias in U.S. House elections in New York State, 1900-2018. 


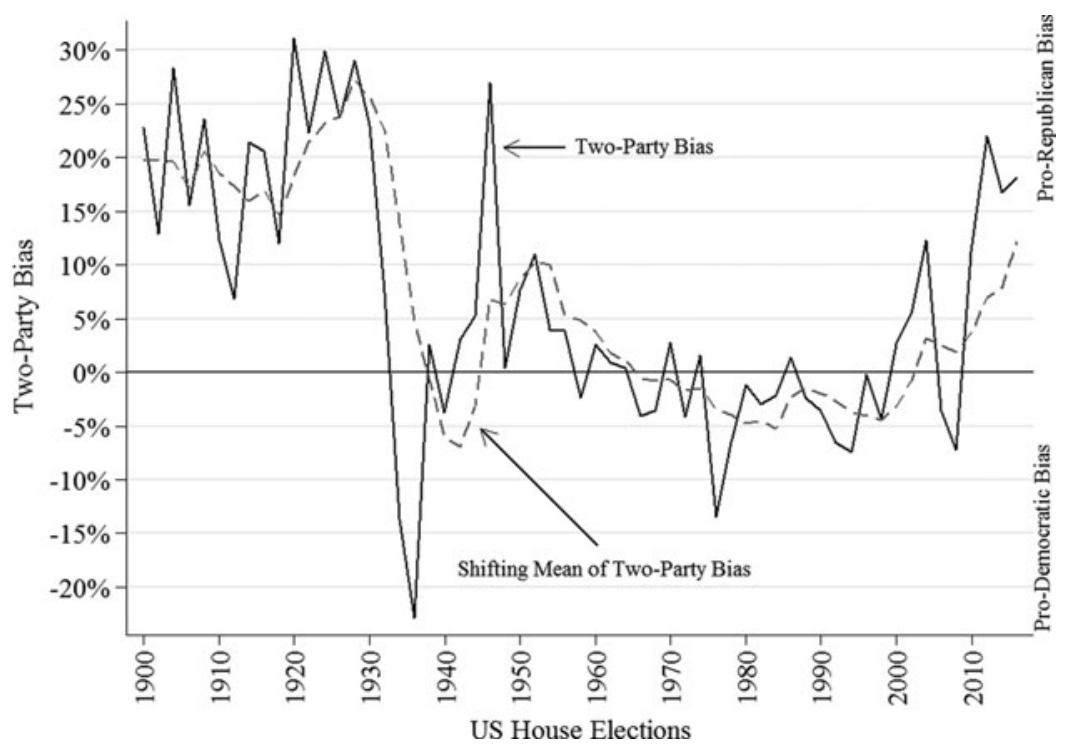

FIG. 3. Two-party bias in U.S. House elections in Pennsylvania, 1900-2018.

experienced a severe, pro-Republican two-party bias in House elections. From 1900 to 1930, there was an average pro-Republican two-party bias of $18 \%$, though by the 1920s it regularly reached around $30 \%$. This pro-Republican bias collapsed in 1932, and by the 1970s the system became much more symmetrical and proportional, with a comparably smaller pro-Democratic bias. (The mean DPIx from 1966 to 2010 was -1.6 , meaning that overall Democrats gained slightly more seats than votes compared to the Republicans during this period.)

However, unlike in New York State, the Pennsylvania results show an anomaly. In 2012, the DPIx jumped to a $22 \%$ pro-Republican bias. The mean DPIx for the three elections since the 2010 reapportionment was 19. During these elections, while Republicans received around $50 \%$ of the vote, they were awarded $72 \%$ of the seats.

As Figure 4 shows, there was a similar jump in the two-party bias in North Carolina. For most of the twentieth century (and, in fact, since Reconstruction), House elections in North Carolina have had a pro-Democratic two-party bias. In the first half of the century, this bias was severe, with the DPIx often reaching -40 . Republicans were effectively completely disenfranchised in this period, with often around $40 \%$ of voters voting for Republican candidates without a single Republican winning a seat. This pro-Democratic two-party bias gradually declined starting in the late 1960s. By the mid-1990s,
House elections in North Carolina became nearly symmetrical. From 1994 until 2010, the DPIx was a -0.5 , meaning that overall there was a very slight pro-Democratic bias.

And then in 2012, the DPIx jumped to a proRepublican bias of $20 \%$. Over the three elections since the 2012 reapportionment, the average DPIx was 22. Over these elections, the Republicans generally received around $52 \%$ of the House vote but won around $74 \%$ of the House seats. The jump of the pro-Republican bias in 2012 is clear, both because of its suddenness and because that change sustained itself in the elections that followed.

This state-level analysis therefore adds to the evidence that elections in Pennsylvania and North Carolina suddenly became significantly more biased towards the Republican Party after the 2012 reapportionment. But at the same time, even in these states, those biases are not historically extraordinary. The pro-Republican bias in House elections in Pennsylvania is now as high as it was in the early decades of the twentieth century, and it is certainly not the highest that this state has seen. What the evidence above suggests is that current bias in the American electoral system is hardly unique to this period of dramatic gerrymandering. Instead, there are likely a range of reasons that this electoral system would bias towards one party instead of the other. The historical evidence suggests instead that this type of bias is endemic to SMP systems, and 


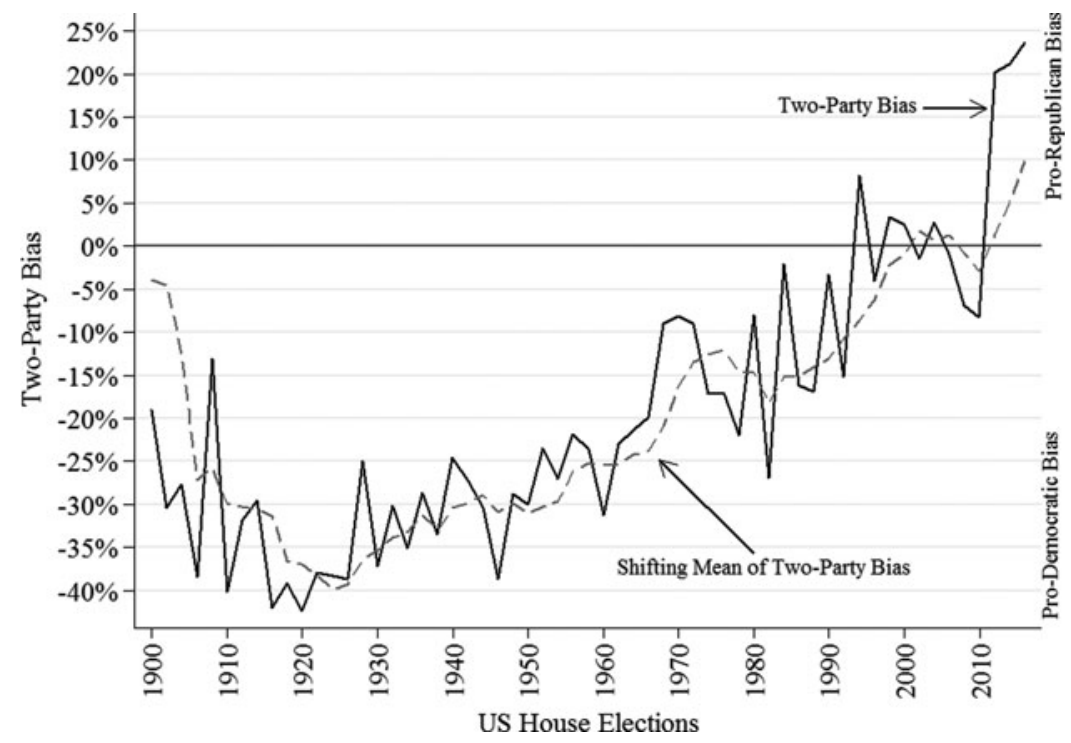

FIG. 4. Two-party bias in U.S. House elections in North Carolina, 1900-2018.

that the reasons why significant two-party bias is occurring can vary widely.

\section{COMPARED TO HYPOTHETICAL PR SYSTEMS}

Would fundamental changes in the American electoral system alleviate this significant two-party bias? One method for determining this is to compare the results above with electoral systems that are supposed to be significantly more proportional, specifically two types of PR. The first type would be a national PR system similar to that of Israel. There would be no districts, but instead all 435 House seats would be determined by proportional representation. The second type would be a state-based PR system. In this case, each state would be treated as a single multimember district, except for those states with only one representative, which would remain the same. The House delegation for each state would be determined by PR.

For this test, I assumed that the distribution of the vote for each party would be identical to the vote that had happened each election. This is important because I am effectively using these votes in PR systems as expected values. The national PR system tells us what the vote would have been had the most proportional system currently available been employed. The state-level PR system tells us how biased the system would have been if each state had the most proportional and symmetrical House elections conceivable. In this way, one can judge not only what fundamental electoral reform might look like, but one can also judge how biased a system would be if each state were capable of running elections without factors like gerrymandering affecting the results.

In both cases, the PR system is assumed to use the D'Hondt method with a $1 \%$ threshold. Specifically, PR systems do not simply allocate seats by dividing. Instead, they perform an iterative function in which each party is gradually allocated seats. In each step, a party is allocated a seat based on the percent votes they received and how many seats they have already been allocated. D'Hondt is one of the two main methods, and it is the method that favors larger parties over smaller parties. Similarly, PR systems always require a minimum vote that parties must receive before being allocated any seats. Thus, if there is a 5\% threshold, a party receiving $4.5 \%$ would be allocated no seats. A $1 \%$ threshold is extremely low. I chose this level to maximize the level of proportionality, and I picked the D'Hondt method because it favors larger parties, since my interest here is in the relative bias of the system between the Democratic and Republican parties.

Figure 5 shows the DPIx for actual House races since 1900 as well as what those DPIx values would have been had there been a national PR (dotted line) and state-level PR (dashed line) electoral 


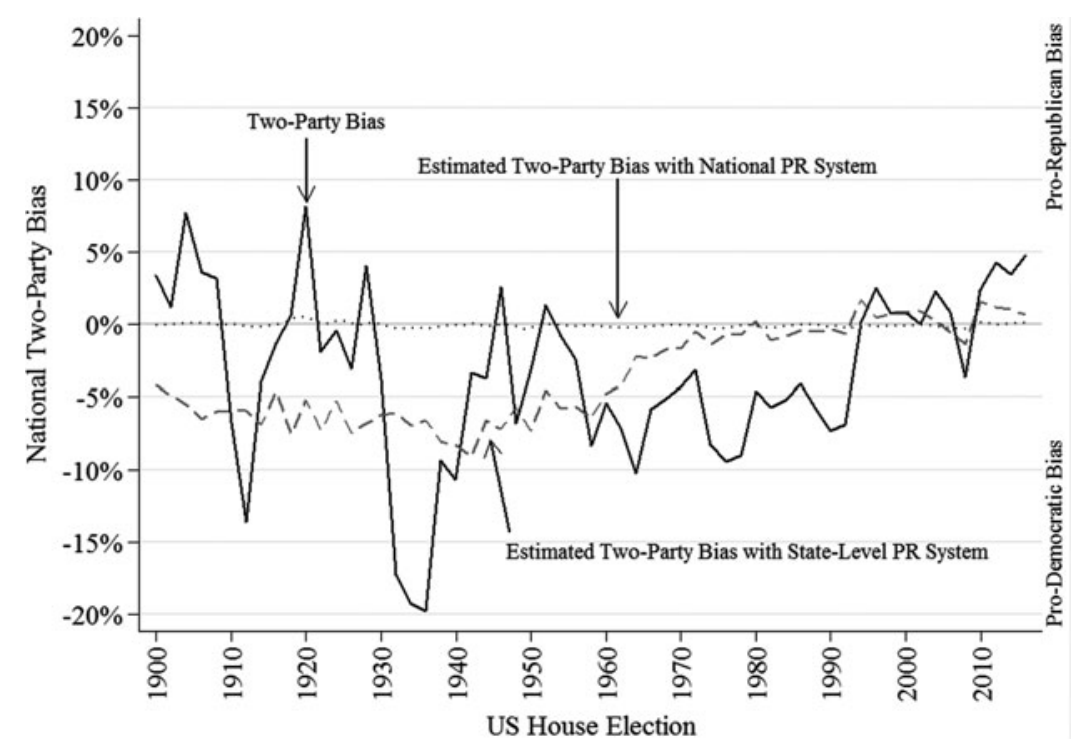

FIG. 5. Two-party bias in U.S. House elections with different electoral systems, 1900-2018.

system. The graph demonstrates that had the United States used a national PR system and the party votes been the same, there would have been virtually no disproportionality between Republican and Democratic candidates and virtually no asymmetry. The mean and median DPIx for this are an extremely small -.02 , meaning that there would have been a very slight pro-Democratic Party bias. Similarly, the two years of greatest disproportionality and bias were 1932, when the Democrats would have gained $.33 \%$ more seats than votes relative to the Republicans, and 1920, when the Republicans would have gained an extra $.56 \%$ seats than votes relative to the Democrats. Indeed, the DPIx values for this system are so small that the dotted line can be barely seen in relation to the line indicating absolute proportionality and partisan symmetry. It therefore effectively shows an overall expected value, or the DPIx for a system that is both proportional and symmetrical. This, of course, is what one might expect.

Less expected are the results for the state-level PR system. The DPIx for hypothetical state-level PR systems show what the overall disproportionality and asymmetry would be if elections were completely fair between the Democratic and Republican parties within each state. The evidence on the graph about the state-PR system suggests several factors about two-party bias in House elections. The first is that for the period from 1900 to 1960 , the designing of any electoral system through federalism would have had a consistently pro-Democratic bias. Moreover, unlike the partisan bias caused by using SMP districts, which often shifted dramatically from election to election, the bias at the state level was consistent and smooth throughout this period. It hovered around a $4 \%$ to a $9 \%$ pro-Democratic bias over this half century.

Second, that state-level Democratic advantage disappeared for the Democrats around 1970. However, the SMP system nonetheless produced a significant pro-Democratic bias from the 1960s until 1994. Despite there being virtually no partisan bias across states during this period, the DPIx from 1970 to 1992 averaged -6, meaning that relative to the Republican Party, the Democratic Party won $6 \%$ more seats than percent votes they received during these two decades.

Third, in the most recent elections, there is a clear pro-Republican bias in the House elections. Moreover, that bias is being caused by issues happening within the states, not across them. Had House elections within the states been proportional and symmetrical, then over the past three elections the average pro-Republican bias (that is, the percent of seats that they would have won over the percent vote they received) would have been only $1 \%$. Instead, over this period, that bias was $4.3 \%$, or an average of 20 extra seats each election.

These results produce a negative picture if one hopes to make American elections fair by making changes at the state level. Overall, these results suggest that the American electoral system has a long 
history of two-party bias that cannot be rectified by removing partisan influence over the drawing of district lines. Instead, partisan bias is likely endemic to any electoral system with small district magnitudes, be it SMP, alternative voting (the electoral system employed by Australia for its House of Representatives), or a purely federalist system in which state governments are central to the design of elections.

\section{DISCUSSION}

In sum, this article presents several new pieces of information that speak to the electoral studies and election law field. The first is that it presents a new index, DPIx, that measures both the disproportionality and bias of an electoral system. To be clear, DPIx is not intended as a challenge against other symmetry measures or more traditional proportionality indexes. Quite the opposite, it is designed as an added tool for researchers to explore the relationship between electoral systems and representation. Gelman and King, for example, provide a powerful, multifaceted estimate that can be used to address a range of questions about SMP elections with two major parties, and the Gallagher index provides a useful summary of proportionality across various systems as well as across time. DPIx is meant to complement these measures, not to act as an approach that is adversarial to existing methods.

Applied to elections to the House of Representatives since 2000, this index shows further evidence that recent elections have led to a bias that increases the voting power of supporters of the Republican Party. However, this evidence also shows that this bias is hardly a recent phenomenon or limited to this period of severe gerrymandering. Instead, that asymmetrical disproportionality was often much more severe, and during the first half of the twentieth century, it favored the Democratic Party to a much greater extreme than the pro-Republican bias is today.

What the results of this study suggest, more than anything, is that the problems with the American electoral system go far beyond gerrymandering. The fact that the U.S. House of Representatives shows a long history of asymmetric disproportionality strongly suggests that fixing the severe gerrymandering that has characterized American legislative politics over the past few decades would likely solve an immediate problem but leave open a future of similar and possibly more significant issues. Indeed, all steps to eliminate intentional manipulation of legislative district lines could be instituted, and nonetheless random fluctuations of the voter base of each major party could cause shifts in proportionality and symmetry that undermine the basic fairness of the voting process.

In the long run, electoral reform in America may turn into a game of political whack-a-mole. Gerrymandering is a symptom of a system built on singlemember districts and federalism. For example, in the 1950s the most serious symptom related to elections in single-member legislative districts was the tendency of states to draw district lines along county borders and thereby produce extremely uneven populations across districts. While this problem had been solved by the courts, that solution opened the door for the gerrymandering problem the United States faces today. As reformers work to minimize the impact of manipulating district lines for political gain, what we do not know is what side effects will emerge in the future. In the end, SMP is a system that can be manipulated towards political ends, and even when it is not, this method of translating votes into seats through many small geographic entities could easily produce unexpected side effects that undermine the equality of the voting process.

Recognizing these problems, some scholars and political activists have argued that more significant electoral reform would dramatically improve representation in the United States. Those proposing electoral reforms have generally moved in two directions (Grofman and Feld 2004). One direction has been to retain single member districts but change from SMP to some form of alternative voting, usually using the name "instant runoff" or "ranked choice voting." The other has been to argue for replacing single-member districts with multimember districts and then changing the voting method to PR, whether some form of list-PR or single-transferable vote (Amy 1997; Barber 2001).

However, electoral reform, notably changing from a majoritarian to proportional system or vice versa, is a politically difficult goal to achieve. Katz (1980) and Nohlen (1984) have argued that significant electoral reform is uncommon and likely to arise only during extraordinary historical situations. While subsequently there have been a handful of major electoral reforms in stable democracies (Renwick 2010), the small number of countries significantly reforming their electoral systems nonetheless still suggests that it is relatively rare. One 
reason is the self-interest of governing parties. Assuming that political parties are seat maximizers, Benoit (2004) argued that electoral reform becomes possible when a governing coalition of political parties believes that the alternative system will bring them more seats than the status quo, circumstances that are unlikely since the status quo system had put these parties into power. To these "contingent" factors, Shugart (2001) argues further that there need to be "inherent" factors as well, such as the electoral system producing such poor results that it appears to be creating systematic failure.

Reform in the United States therefore faces steep obstacles. For this reason, the determination of what reform to promote faces two main questions. The first is how each type of reform would affect representation, or more specifically, how it would impact both proportionality and partisan symmetry. The second is the difficulty of enacting the reform. Despite the numerous obvious flaws of the current system in the United States, there are a range of factors that could make implementing a new system difficult. Representatives, who often make a career by building support in legislative districts, would put themselves into a strategically weaker position by supporting a switch to list-PR. For American voters, any change in the system, especially one that makes voting more complicated, could be difficult and lead to a backlash, as it did after Burlington, Vermont, temporarily experimented with instant runoff.

Finally, reformers of the American political system face constitutional issues. Like many political issues in the United States, the Constitution provides mixed requirements on how elections should be conducted. On the one hand, the Constitution provides the states the power to select electors to the United States Congress in Sections 2 and 4 of Article 1, which was reiterated in modified form by the 14th Amendment. On the other hand, Congress itself can determine rules that regulate how those seats are allocated. The Apportionment Act of 1842, passed by Congress, disallowed states from creating multimember districts, for example, a requirement that was reiterated and enforced through the SingleMember District Mandate of 1967 (Tamas 2006). At the same time, the way elections are conducted is expected to meet the principles of "one person, one vote," which is rooted in the Equal Protection Clause of the Fourteenth Amendment.

These obstacles combined with the results presented above show a picture of how favorable par- ticular electoral reforms might be, at least as they relate to proportionality and symmetry, as well as how possible their enactment might be. For example, these results suggest that the current American electoral system is likely to produce severe disproportionality and asymmetry, regardless of how well policymakers solve specific issues like gerrymandering. However, this system is highly beneficial to current members of Congress, as well as to state legislators, since their careers are built on using this structure, and the current combination of gerrymandered districts and candidate-centered campaigns has significantly improved the career prospect of those already in Congress. Similarly, SMP requires no change of behavior among voters, most of whom are not even aware of the various ways elections are run globally. The current SMP system also complies with federalism, since most of the decisions on how representatives are elected are determined by the states.

The opposite conclusion could be reached with a national PR system, or one in which there are no district lines and all members of the House of Representatives are selected off party lists. As Figure 5 strongly suggests, this would be a highly proportional and symmetrical system. However, the obstacles to this type of reform are surely insurmountable. Such a change would ask members of Congress and state legislatures to vote for a system that dramatically reduces their likelihood of winning reelection, and since this system would also likely lead to an increase in the number of effective parties in the United States (Duverger 1954), it is very unlikely that the Republican and Democratic party leaderships would ever support such a change. At the same time, it would fundamentally change the way that Americans vote as well as relate to their representatives. Finally, such a system would eliminate any role of state governments in the election process, a change that is very unlikely to be deemed constitutional by the courts.

A compromise position by proponents of PR, like Amy (2002), would be a state-level PR system. In this system, states would still administer House elections, but instead of having the state delegation selected by single-member districts, they would be selected via a statewide PR system. The primary advantage of this system is that it applies PR without challenging the federalism aspect of American election law. However, as the results shown above demonstrate, a state-level PR system would likely still produce 
significant disproportionality and asymmetry. In other words, for elections to the House of Representatives, California, Texas, New York, Florida, and other larger states would likely have proportional and symmetrical systems, but smaller states with odd numbers of representatives might consistently send more representatives of one party, which could translate to a significant bias in its favor.

Indeed, the dashed line in Figure 5 demonstrates this problem. While the evidence suggests that a national PR system would be highly proportional and symmetrical, and while the current SMP system had widely varying levels of partisan bias since 1900 , a state-based PR system would have likely produced a consistently Democratic bias through most of the twentieth century. In recent elections, this asymmetry has diminished dramatically, though this state-based PR system would still likely be producing a Republican bias today. If the vote were the same but this state-level PR system had been used, since the 2010 election the Republican Party would have gained an average of approximately five seats per election.

Effectively, this suggests that the only way to reform the American system to eliminate significant asymmetrical disproportionality while retaining federalism is through compensatory seats. Compensatory seats are a mechanism commonly used by democracies that conduct PR elections in regional districts, like Sweden and Denmark. Since simply allocating seats based on the results of these regional elections can produce disproportionality, these countries set aside a certain number of seats that are meant to correct it, including by awarding more seats to parties underrepresented compared to the percent vote they received. In Germany, which has single-member districts, voters make two choices, one for the local representative and the other for a party list. The seats allocated to party lists are then used to offset the disproportionality that occurs within the single-member districts.

Adding compensatory seats to the House of Representatives could significantly improve proportionality and symmetry but otherwise leave the system as it currently stands. In other words, the current system of House districts would be left unchanged, and voters would vote for individual candidates as they do today. But then, based on the percent vote for each party across all House districts, each party would be allocated compensatory seats to offset the disproportionality and partisan bias caused by single-member district elections. This system would also likely increase the number of seats won by third parties, and it would significantly reduce the partisan advantage of gerrymandering, since any partisan gain produced by manipulating district lines would be offset through compensatory seats.

The compensatory seat system would solve many of the problems with other reform proposals. Because it retains the current SMP system but adds PR compensatory seats to correct its disproportionality and asymmetry, this system has the least negative impact on voters and politicians. The system requires no changes in the way that Americans vote for members of the House of Representatives, and since the existing SMP system and its congressional districts remain intact, it creates no threat to legislative careers. Quite the opposite, this system would likely increase the security of lawmakers, since it would provide them an added method for retaining a seat in Congress. Because it keeps state delegations, this system also provides a potential mechanism for balancing the government's interests in both promoting proportionality and allowing states to conduct elections for their state delegations.

None of this diminishes the importance of current attempts at electoral reform, including to eliminate gerrymandering. But the findings in this article put these attempted reforms into a historical context. The findings of this article suggest that SMP will lead to asymmetrical disproportionality, and both electoral manipulation and random fluctuations could make that bias severe, which would lead to some voters having greater influence over the government than others. In the long run, short of producing some form of PR, these fundamental issues with the American electoral system will likely keep reemerging, though possibly for different specific reasons each time.

\section{REFERENCES}

Amy, Douglas J. 1997. Full Representation: The Case for a Better Election System. Northampton: Crescent Street Press.

Amy, Douglas J. 2002. Real Choices/New Voices: How Proportional Representation Elections Could Revitalize American Democracy. New York: Columbia University Press.

Baker v. Carr. 1962. 369 U.S. 186.

Barber, Kathleen L. 2001. A Right to Representation: Proportional Election Systems for the Twenty-First Century. Columbus: Ohio State University Press. 
Benoit, Kenneth. 2004. "Models of Electoral System Change." Electoral Studies 23: 363-89.

Downs, Anthony. 1957. An Economic Theory of Democracy. New York: Harper.

Dubin, Michael J. 1998. United States Congressional Elections, 1788-1997. Jefferson: McFarland.

Duverger, Maurice. 1954. Political Parties: Their Organization and Activity in the Modern State. Translated by Barbara and Robert North. New York: John Wiley \& Sons.

Epstein, Leon D. 1967. Political Parties in Western Democracies. New York: Praeger.

Farrell, David M. 2011. Electoral Systems: A Comparative Introduction. 2nd. London: Palgrave Macmillan.

Gallagher, Michael. 1991. "Proportionality, Disproportionality and Electoral Systems." Electoral Studies 10(1): 33-51.

Gallagher, Michael, and Paul Mitchell. 2005. "Introduction to Electoral Systems." In The Politics of Electoral Systems, by Michael Gallagher and Paul Mitchell, 3-23. Oxford: Oxford University Press.

Gelman, Andrew, and Gary King. 1990. "Estimating Incumbency Advantage Without Bias." American Journal of Political Science 34(4): 1142-64.

- 1994. "A Unified Method of Evaluating Electoral Systems and Redistricting Plans." American Journal of Political Science 38(2): 514-54.

Grofman, Bernard, and Gary King. 2007. "The Future of Partisan Symmetry as a Judicial Test for Partisan Gerrymandering after LULAC v. Perry." Election Law Journal 6(1): 2-35.

Grofman, Bernard, and Scott L. Feld. 2004. "If You Like the Alternative Vote (a.k.a. the Instant Runoff), Then You Ought to Know about the Coombs Rule." Electoral Studies 23: 641-59.

Katz, Richard S. 1980. A Theory of Parties and Electoral Systems. Baltimore: Johns Hopkins University Press.

Lijphart, Arend. 1994. Electoral Systems and Party Systems: A Study of Twenty-Seven Democracies, 1945-1990. Oxford: Oxford University Press.

Loosemore, John, and Victor J. Hanby. 1971. "The Theoretical Limits of Maximum Distortion: Some Analytic Expressions for Electoral Systems." British Journal of Political Science 1(4): 467-77.

Monroe, Burt L. 1994. "Disproportionality and Malapportionment: Measuring Electoral Inequality." Electoral Studies 13(2): 132-49.
Nohlen, Dieter. 1984. "Changes and Choices in Electoral Systems." In Choosing an Electoral System: Issues and Alternatives, by Arend Lijphart and Bernard Grofman. New York: Praeger.

Renwick, Alan. 2010. The Politics of Electoral Reform: Changing the Rules of Democracy. New York: Cambridge University Press.

Reynolds v. Sims. 1964. 377 U.S. 533.

Rosenstone, Steven J., Roy L. Behr, and Edward H Lazarus. 1984. Third Parties in America: Citizen Response to Major Party Failure. Princeton: Princeton University Press.

Seabrook, Nicholas R. 2017. Drawing the Lines: Constraints on Partisan Gerrymandering in U.S. Politics. Ithaca: Cornell University Press.

Shugart, Matthew S. 2001. "“Extreme' Electoral Systems and the Appeal of the Mixed-Member Alternative." In MixedMember Electoral Systems: the Best of Both Worlds?, by Matthew S. Shugart and Martin P. Wattenberg, 25-54. New York: Oxford University Press.

Stephanopoulos, Nicholas O., and Eric M. McGhee. 2015. "Partisan Gerrymandering and the Efficiency Gap." University of Chicago Law Review 82(2): 831-900.

Tamas, Bernard. 2006. "A Divided Political Elite: Why Congress Banned Multimember Districts in 1842." New Political Science 28: 23-44.

- 2018. The Demise and Rebirth of American Third Parties: Poised for Political Revival? New York: Routledge.

Address correspondence to: Bernard Tamas

Department of Political Science Valdosta State University 1500 N. Patterson Street Valdosta, GA 31698

E-mail: bitamas@valdosta.edu

Received for publication July 4, 2017; received in revised form March 7, 2018; accepted August 30, 2018; published online February 8, 2019. 